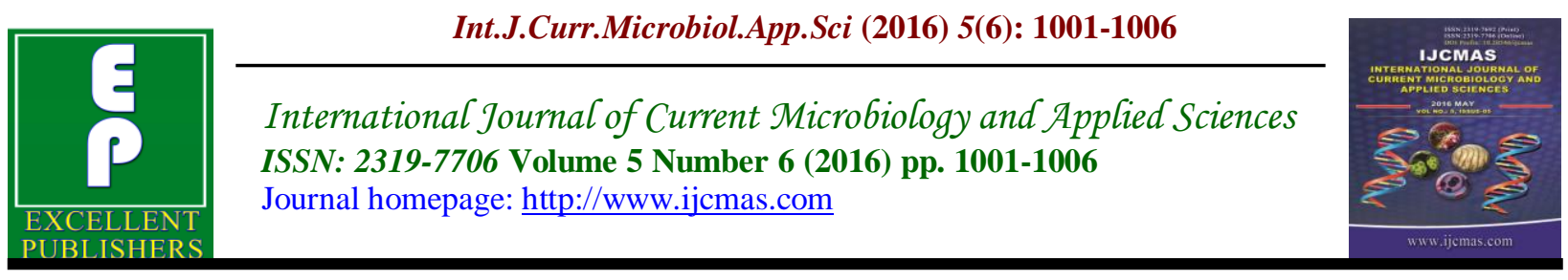

Original Research Article

http://dx.doi.org/10.20546/ijcmas.2016.506.106

\title{
Detection of Biofilm Coding icaD Gene in Methicillin Resistant Staphylococcus aureus (MRSA) Isolated from Patients undergoing Tonsillectomy in Basra City
}

\author{
Abdulameer Abdullah Al-Mussawi* \\ College of Nursing, University of Basra, Basra, Iraq \\ *Corresponding author
}

\begin{abstract}
A B S T R A C T
\section{Keywords}

Biofilm, icaD gene,

Methicillin

Resistant

Staphylococcus

aureus, MRSA,

tonsillectomy,

CHROMagar, Basra

\section{Article Info}

Accepted:

15 May 2016

Available Online:

xx June 2016

The aim of the present study was to detect biofilm formation of Methicillin Resistant Staphylococcus aureus (MRSA) by two methods. One hundred forty two bacterial isolates were obtained from the core of (63) infected tonsils collected from Al-Basra General Hospital in Basra city, cultured on orientation chromagar.34 isolates were identified as Staphylococcus aureus, out of which 33 isolates were identified as MRSA by using CHROMagar MRSA. Biofilm formation of the 33 MRSA isolates were screened by Congo red agar (CRA) and iced gene detection. Thirty three isolates out of 34 isolates (97\%) were identified as $S$. aureus, and 33 isolates (100\%) as MRSA on CHROMagar media. The females (19 patients) were more than males (14 patents) with percentages $(57.6 \%, 42.4 \%)$ respectively. Twenty patients aged from (1-9 years), nine patients aged from (10-19 years), three aged from (20-29 years), and one patient aged from (30-39 years) represented $(58.8 \%, 29.4 \%, 8.8 \%$ and $3 \%)$ respectively. Fourteen $(42.4 \%)$ isolates showed a black crystalline morphology, indicating biofilm production was observed on Congo red agar and 33(100\%) in molecular method by detection of icaD gene. The molecular methods gave the most accurate to determine the MRSA producing of biofilm compared routine methods.
\end{abstract}

\section{Introduction}

Tonsillitis is a common disease of childhood and adolescence. The diagnosis of tonsillitis must generally consider Group A betahemolytic Streptococcus (GABHS) infection. Many other bacteria alone or in combinations, viruses and other infections and non-infectious causes should be considered. Determination of the cause and choice of suitable therapy is important in assuring rapid recovery and preventing complications (Thuma, 2001).
An abscess may develop lateral in the tonsil several days after the onset of tonsillitis. This is termed a peritonsillar abscess. Rarely, the infection may spread beyond the tonsil causing inflammation and infection of the internal jugular vein leading to a spreading septicemia infection (Lemierre's syndrome) (Thuma, 2001).

The ability to form biofilms is one of the reasons these organisms are able to protect themselves against host immune systems 
(Leid et al., 2002; Patel, 2005). The interior of the bacterial biofilms shows greater resistance to the opsonization by antibodies and to phagocytosis, which explains the chronic nature of these infections (Dunne, 2002). Formation of biofilm is a multistep process, beginning with transient adherence to a surface. Subsequently, certain bacterial adhesins, called microbial surface components recognizing adhesive matrix molecules encourage the actual attachment (Foster and Hook, 1998). Then, during the accumulation phase, the bacteria adhere to each other and generating extracellular polymeric substances (EPS) and/or incorporation of host derived components, such as platelets, carried out, leading to a mature biofilm. In cases of nutrient deficiency, or at high cutting forces, a detachment of bacteria appears through autonomous formation of autoinducing peptides (Boles and Horswill, 2008), with release and spread of bacteria as a result. It was found that expression of the locus of accessory gene regulator ( $a g r)$, encoding a quorum-sensing system, leads in expression of surfactant-like molecules, such as $\delta$ toxin (Vuong et al., 2000), contributing to the detachment.

Molecular techniques have recently been known for the detection of the genes responsible for the slime exopolysaccharide component of biofilms, also called polysaccharide intercellular adhesin (PIA).

PIA is made up of a linear 1,6-linked glycosaminoglycan and synthesised in vitro from UDP- $N$-acetylglucosamine by $N$ acetylglucosaminyltransferase, which is encoded by the intercellular adhesion (ica) locus, mainly by the icaA gene. Coexpression of icaA and icaD genes resultsin the complete phenotypic expression of the capsular polysaccharide (Vasudevan et al., 2003).
The aim of the present study was to detect biofilm formation of methicillin resistant Staphylococcus aureus (MRSA) isolates by CRA and PCR methods.

\section{Methodology}

Sixty three core tonsils cultures for aerobic bacteria were obtained from 63 patients who had tonsillectomy because of recurrent tonsillitis in Al-Basra General Hospital in Basra city during (1 October to 31 December 2015).

142 bacterial isolates were obtained by culturing swap samples of the core of (63) infected tonsils on brain heart infusion broth (Himedia, India) and then on CHROMagar orientation (CHROMagar ${ }^{\mathrm{TM}}$, Paris, France). $S$. aureus isolates(34 isolates) appeared as white colonies. S. aureus isolates then have been inoculated on CHROMagar MRSA (CHROMagar $^{\mathrm{TM}}$, Paris, France). Biofilm formation of the 33 MRSA isolates were screened by Congo red agar (CRA) and icaD gene method.

\section{Congo Red Assay Method}

This method is based on the characteristic cultural morphology of biofilm-forming bacteria on Congo red medium. The medium was composed of brain heart infusion broth (BHI) (Oxoid Ltd, Hampshire, England) 37 $\mathrm{g} / \mathrm{l}$, sucrose $50 \mathrm{~g} / \mathrm{l}$, agar No 1 (Oxoid Ltd, Hampshire, England) $10 \mathrm{~g} / \mathrm{l}$ and Congo red (BDH Chemical Ltd, Poole, England) 0.8g/l. Congo red stain was made ready as a strong aqueous solution and sterilized $\left(121^{\circ} \mathrm{C}\right.$ for 15 minutes) separate from the rest of the medium components and supplemented to the agar when the temperature reached $55^{\circ} \mathrm{C}$. Agar plates were prepared and inoculated and kept in the incubator for 24 hours at $37^{\circ} \mathrm{C}$. The production of black colonies with a dry crystalline consistency 
by the organisms was taken to indicate biofilm production as non-biofilmproducing strains develop red colonies (Mathur et al., 2006).

\section{IcaD Gene Method}

Genomic DNA was extracted by the kit supplemented by the manufacturing company (Bioneer-Korea). PCR amplification of the $i c a D$ gene was carried out using the following primers: icaD -F, 5 ATGGTCAAGCCCAGACAGAG-3' ; icaDR, 5 CGTGTTTTCAACATT TAATGCAA3 (Bioneer, Korea), generating an amplification product of $198 \mathrm{bp}$. The reaction mixture $(25 \mu l)$ contained $5 \mu \mathrm{l}$ DNA template, $1 \mu \mathrm{l}$ Forward primer, $1 \mu 1$ Reverse primer, $12.5 \mu 1$ Master $\operatorname{mix}$ and $5.5 \mu 1$ Nuclease free water. Amplifications were performed in a thermal cycler (Peqlab, Germany) using the following program : an initial denaturation at $94^{\circ} \mathrm{C}$ for 5 minutes, followed by 50 cycles of 30 seconds denaturation at $94^{\circ} \mathrm{C}, 30$ seconds annealing at $55.5^{\circ} \mathrm{C}$ and 30 second extension at $72^{\circ} \mathrm{C}$ followed by 1 minute at $72^{\circ} \mathrm{C}$. The amplification products were separated on 1 $\%$ agarose gel, stained with ethidium bromide (Fisher, USA).

\section{Results and Discussion}

All organisms tested grew on CHROM agar Orientation plates and incubated at 35 to $378 \mathrm{C}$ for 16 to $24 \mathrm{~h}$. There was a consistent color reaction observed for some species or genus.

Thirty three isolates out of 34 isolates (97\%) appeared as white colonies were identified as $S$. aureus and appeared as pink identified as MRSA on CHROM agar MRSA (Fig.1). The females (19 patients) were more than males (14 patents) with percentages $(57.6 \%$, $42.4 \%$ ) respectively. Twenty patients aged from (1-9 years), nine patients aged from (10-19 years),three aged from (20-29 years), and one patient aged from (30-39 years) represented $(58.8 \%, 29.4 \%, 8.8 \%$ and $3 \%$ ) respectively (Table 1$)$.

\section{Study of Biofilm Formation on Congo Red Agar Plates}

Fourteen (42.4\%) isolates showed a black crystalline morphology, indicating biofuel production was observed in plates (Fig. 2).

\section{Study of Biofilm Formation by Molecular Method (Detection of icaD gene).}

All MRSA isolates were positive for biofilm formation by molecular method by PCR amplification of icaD gene (Fig. 3).

Staphylococcus aureus is one of the most frequently identified pathogens in clinical laboratories, while methicillin-resistant $S$. aureus (MRSA) is an important nosocomial pathogen (Merlino et al., 1996).

CHROM agar Staph. aureus compared favorably to conventional media for rapid detection of $S$. aureus in clinical samples, This medium has the potential to more rapidly and accurately identify patient samples (Flayhart et al., 2004).

Fig.(1) showed pink colonies of MRSA on CHROM agar MRSA and Table (1) showed the more infected tonsills by MRSA in age group (1-9) years, this may caused by misuse of antibiotics, giving antibiotics for a long time, or give antibiotics when the child does not need them. All these can cause bacteria to become resistant. MRSA is more likely to cause an infection child has a weak immune system. A woman who has MRSA may give it to the baby from birth and breast-feeding. 
Table.1 MRSA isolates according to age group and gender of patients

\begin{tabular}{|l|l|l|l|}
\hline Age group & Male & Female & Percentage \\
\hline 1-9 years & 8 & 11 & $60.7 \%$ \\
\hline 10-19 years & 4 & 6 & $27.3 \%$ \\
\hline 20-29 years & 1 & 2 & $9 \%$ \\
\hline 30-39 years & 1 & 0 & $3 \%$ \\
\hline Total & 14 & 19 & $100 \%$ \\
\hline
\end{tabular}

Table.2 Comparison of the production of biofilm by clinical isolates of Staphylococcus aureus by two methods

\begin{tabular}{|l|l|l|}
\hline \multirow{2}{*}{ Methods } & \multicolumn{2}{|c|}{ MRSA (n=33) } \\
\cline { 2 - 3 } & + & $(\%)$ \\
\hline Congo red agar method & 13 & 39.3 \\
\hline Molecular method & & \\
\hline
\end{tabular}

Fig.1 Pinkcolonies of MRSA on CHROM agar MRSA

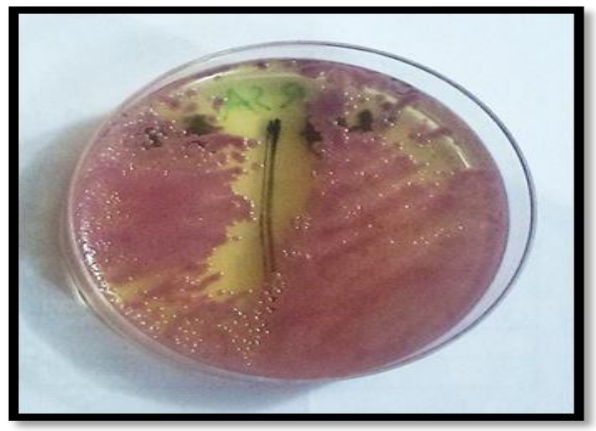

Fig.2 Congo Red Agar (CRA) assay for S. aureus isolate from core of tonsills. Positive is black colonies with dry crystalline (slime producers)

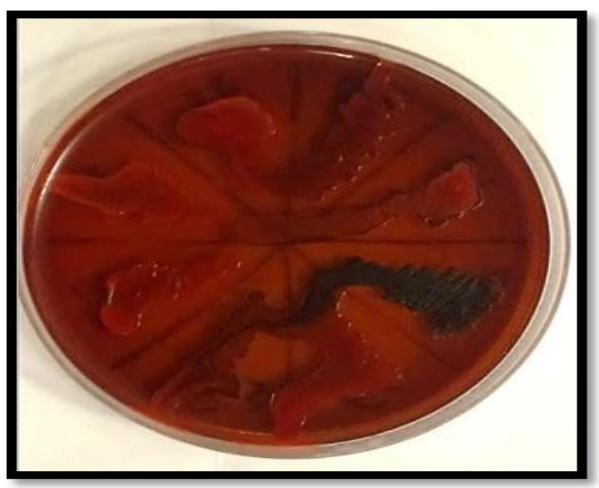


Fig.3 Gel electrophoresis indicating the presence of icaD gene (198bp)

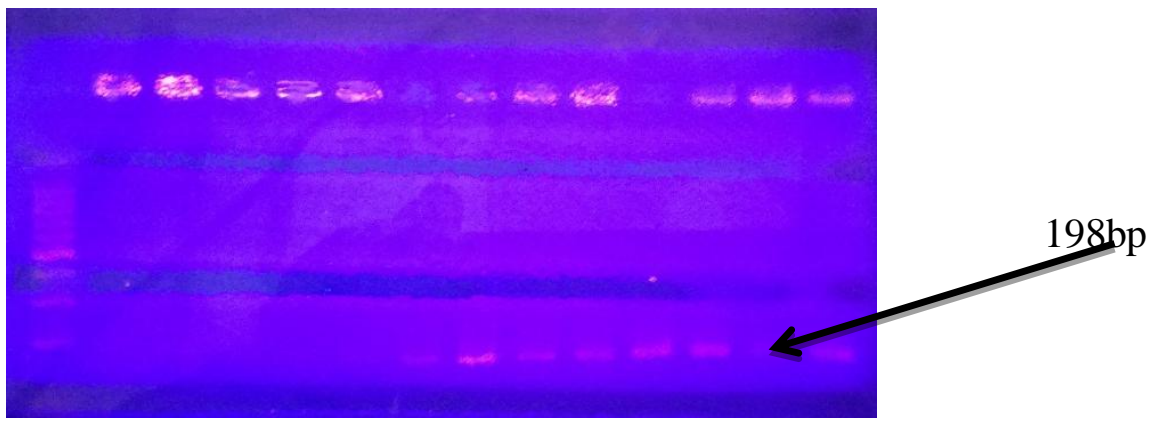

Some strains can cause chronic infections and gain increased resistance to antimicrobial agents through biofilm formation (Chen and Wen, 2011). Researchers have investigated the strategies employed by microorganisms to produce biofilms and to understand the pathogenesis. They discovered that biofilm-producing bacteria secrete certain chemicals that protect them from disinfectants and antimicrobials, and phagocytic host immune systems (Saitou et al., 2009).

In view of the large number of infections caused by biofilm producing bacterial, a reliable method for their diagnosis is necessary (Oliveira and Cunha, 2010). Qualitative methods, such as the CRA method described by Freeman et al. (1989), used in routine laboratories. Molecular methods such as the PCR, which amplifies the genes involved in biofilm production complement these methods. Molecular methods considered modern methods of use in modern laboratories and more than confirm the diagnosis of routine biofilm methods.

The CRA method is easier and faster to perform than other phenotypic methods. However, it is slightly imprecise in the identification of positive isolates when compared to molecular analysis of the genes involved in biofilm production, a fact also observed by Fitzpatrick et al. (2005).
The results showed that the molecular methods gave the most accurate to determine the MRSA producing of biofilm compared routine methods(Table. 2).Similar results have been reported in the study of Arciola et al.(2002).

\section{References}

Arciola C.R., Campoccia D., Gamberini S., Cervel-Lati M., Dontati E. and Montanaro L. (2002). Detection of slime production by means of an optimized Congo red agar plate based on a colourimetric scale in Staphylococcus epidermidis clinical isolates genotyped for ica locus. Biomaterials.23:4233-239.

Chen L. and Wen Y.M. (2011). The role of bacterial biofilm in persistent infections and control strategies. Int J Oral Sci 3: 66-73.

Dunne W.M. (2002). Bacterial adhesion: see any good biofilms lately? Clin Microbiol Rev 15: 155-66.

Fitzpatrick F., Humphreys H. and O'Gara P. (2005). Evidence for icaADBCindependent biofilm development mechanism in methicillin-resistant Staphylococcus aureus clinical isolates. J Clin Microbiol.43:19731976.

Flayhart D., Lema C. Borek A. and Carroll K. C. (2004). Comparison of the BBL CHROMagar Staph aureus 
Agar Medium to Conventional Media for Detection of Staphylococcus aureus in Respiratory Samples. J Clin Microbiol. 42(8): 3566-3569.

Foster T.J. and Hook M. (1998). Surface protein adhesins of Staphylococcus aureus. Trends Microbiol. 6(12):484-488.

Freeman D.J., Falkner F.R. And Keane C.T. (1989). New method for detecting slime production by coagulasenegative staphylococci. J Clin Pathol. 42:872-874.

Leid J.G., Shirtliff M.E., Costerton J.W. and Stoodley A.P. (2002). Human leukocytes adhere to, penetrate, and respond to Staphylococcus aureus biofilms. Infect Immun 70: 63396345.

Merlino J, Gill R, Robertson G J. Application of lipovitellin-saltmannitol agar for screening, isolation, and presumptive identification of Staphylococcus aureus in a teaching hospital. J Clin Microbiol. 1996;34:3012-3015.

Mathur T., Singhal S., Khan S., Upadhyay D.J., Fatma T. and Rattan A. (2006) Detection of biofilm formation among the clinical isolates of staphylococci: an evaluation of three different screening methods. Indian $\mathbf{J}$ Med Microbiol. 24: 25-29.
Oliveira A., Cunha M. (2010). Comparison of methods for the detection of biofilm production in coagulasenegative staphylococci. BMC Res Notes. 3, p. 260.

Patel R. (2005). Biofilms and antimicrobial resistance. Clin Orthop Relat Res 437: 41-47.

Saitou K., Furuhata K., Kawakami Y., Fukuyama M. (2009). Biofilm formation abilities and disinfectant resistance of Pseudomonas aeruginosa isolated from cockroaches captured in hospitals. Biocontrol Sci. 14: 65-68.

Thuma P. (2001). "Pharyngitis and tonsillitis". In Hoekelman, Robert A. Primary pediatric care. St. Louis: Mosby. ISBN 0-323-00831-3.

Vasudevan P., Nair M.K.M., Annamalai T., Venkitanarayanan K.S. (2003). Phenotypic and Genotypic characterization of bovine mastitis isolates of Staphylococcus aureus for biofilm formation. Vet. Microbiol. 92:179-185.

Vuong C., Saenz H.L., Gotz F., Otto M. (2000). Impact of the agr quorumsensing system on adherence to polystyrene in Staphylococcus aureus.J Infect. Dis. 182(6):16881693.

\section{How to cite this article:}

Abdulameer Abdullah Al-Mussawi. 2016. Detection of Biofilm Coding icaD Gene in Methicillin Resistant Staphylococcus aureus (MRSA) Isolated from Patients undergoing Tonsillectomy in Basra City. Int.J.Curr.Microbiol.App.Sci. 5(6): 1001-1006. doi: http://dx.doi.org/10.20546/ijcmas.2016.506.106 